\title{
Editorial: Hot topics in planning
}

Elisabete A. Silva PhD, FRICS, MRTPI

Chairperson, Editorial Advisory Panel and Senior Lecturer, Department of

Land Economy, University of Cambridge, UK

\section{Digital cities and cyberspace}

There was a time when cyberspace belonged to the arena of science fiction, nowadays it is seamlessly integrated into the physical and social fabric of society. The February 2013 issue of Urban Design and Planning focused on information and communication technologies and cyberspace plays an important role in this emergent subject. The concept of society in itself has changed in order to include the new dimension of cyberspace. As a consequence, planning cannot ignore such a concept; theory, policy and practice need to accept its importance, not only just to 'cope' with it but to fully explore its potential in order to advance socio-economic and environmental sustainability. Apostol et al. (2013) stress the importance of this new concept and propose a conceptual framework for planning and design practice to incorporate self-consciously the hybrid space of the virtual and physical. This is an important area, pivotal in today's world and clearly neglected in some planning fields.

\section{Resilience and mitigating}

The concept of an urban heat island (UHI) has been around for many decades as a tool to understand why and how the urban-countryside behaved in terms of absorbing and emitting energy. Later, that scientific curiosity moved towards more action-oriented concepts linking it with comfort and health. Hamilton et al. (2013) present a comprehensive overview of the development of the UHI, using a case study of London to assess the impact of the UHI on health, comfort and energy use. As the authors note 'In order to assess the impact that new and existing developments have on the UHI, planners and designers need analysis tools that are capable of robustly and quantitatively assessing the interrelationships between the urban form and the UHI at various spatial scales in addition to qualitative best practice guidance' (p.2). The authors propose a UHI assessment framework which is of use to all of us working with urban design and planning.

\section{Property and planning}

Long gone is the time when property was just about the building in itself, the square feet it provided and the quality of materials and finishing. Property isn't just about concrete and finance; if the layout of the urban matrix can increase or reduce property values, improve quality of life and increase our enjoyment of the city, understanding the variables and dynamics involved in property is key.
Something that in the past would be difficult to argue for is now at the centre of important research, from hedonic finance methods to fully operational software and methodologies it is finally possible to plan our cities using a more holistic and sustainable view of property and spatial planning. That is exactly what the paper by Chiaradia et al. (2013) tries to do using a fully operational computer model and a set of metrics and methodologies of space syntax. The paper determines the role of urban street layout design in the variation of property values. Using space syntax fine-grained spatial design analysis the patterns of property prices are analysed for a large contiguous sample of over 60000 residential buildings in a North London borough, using the council tax band as a proxy variable for the property price.

\section{The come back to the city - cultural life of public spaces}

Many of the dying cities of the 1970s and 1980s suffered a recent resurgence and are now in full bloom. During the turn of the century and nowadays city centres have becone vibrant with activities, they are considered the engines of growth and innovation, and the future of modern societies. The role public spaces play in this new city is pivotal, nevertheless, there are problems. Research in the UK tends to emphasise the fact that urban parks are underfunded and neglected. In the opening briefing, Pugalis (2013) drawing on his experience, reports on the (ongoing) production of public spaces and extracts pointers for best practice. Underutilisation, temporal dimensions and perceptions of urban quality are analysed, before tentatively considering future directions. Multi-stakeholder coproduction is put forward as a potentially fruitful mode of working.

\section{REFERENCES}

Apostol I, Antoniadis P and Banerjee T (2013) Cyberspace design: a new challenge for planners. Proceedings of the Institution of Civil Engineers - Urban Design and Planning 166(3): 156-163, http://dx.doi.org/10.1680/udap.11.00004.

Chiaradia A, Hillier B, Schwander C and Barnes Y (2013)

Compositional and urban form effects on residential property value patterns in Greater London. Proceedings of the Institution of Civil Engineers - Urban Design and Planning 166(3): 176-200, http://dx.doi.org/10.1680/udap. 10.00030 .

Hamilton IG, Davies M and Gauthier S (2013) London's urban 
heat island: a multi-scaled assessment framework

Proceedings of the Institution of Civil Engineers - Urban Design and Planning 166(3): 164-175, http://dx.doi.org/10. 1680/udap.10.00046.
Pugalis L (2013) Briefing: The cultural life of public spaces. Proceedings of the Institution of Civil Engineers - Urban Design and Planning 166(3): 151-155, http://dx.doi.org/10. 1680/udap.10.00057. 